\title{
Off-State Gate Leakage Current in N-Channel MOSFET's with Gate Dielectrics Prepared by Different Techniques.
}

\author{
Zeng $\mathrm{Xu}$, P. T. Lai, and W. T. $\mathrm{Ng}^{+}$ \\ Department of Electrical and Electronic Engineering, University of Hong Kong. \\ ${ }^{+}$Department of Electrical and Computer Engineering, University of Toronto, Canadia.
}

\section{Introduction}

Drain corner-field induced band-to-band (B-B) tunneling in thin-oxide MOSFET's has been identified as a fundamental limit in MOS device scaling [1]-[3]. The LDD structure provides a simple solution to this drain leakage problem [2], [3]. Under the same bias condition, gate current $\left(\mathrm{I}_{\mathrm{g}}\right)$ is also observed for a wide range of oxide thickness. This charge transport through oxide in the gate-drain overlap region plays an essential role in electrical erase for a class of non-volatile memories commonly known as "flash EEPROM's" [4]-[6]. However, it also raises the issue of device degradation and gate oxide breakdown because it can lead to charge trapping in the oxide. The origin of this off-state gate current in $\mathrm{SiO}_{2}$-gate n-channel MOSFET's, which occurs at high drain voltages, has been attributed to Fowler-Nordheim (F-N) tunneling of electrons from the gate for $\mathrm{SiO}_{2}$ thinner than $100 \AA$, and to hot-hole injection from the drain for thicker $\mathrm{SiO}_{2}$ [3], [7]. For $\mathrm{NH}_{3}$-nitrided gate oxide (NO) prepared by rapid thermal nitridation (RTP), a significant $\mathrm{I}_{\mathrm{g}}$ at drain voltages as low as $4 \mathrm{~V}$ and $\mathrm{I}_{\mathrm{g}}$ injection efficiency as high as 0.8 were reported in the n-channel MOSFET's [8]. On the other hand, an $\mathrm{N}_{2} \mathrm{O}$-based nitridation technology has been extensively studied recently as a more promising alternative to $\mathrm{NH}_{3}$ nitridation because of its simpler processing and absence of detrimental H-related species in the nitridation ambient [9]-[12]. Nevertheless, the off-state $I_{g}$ characteristics in MOSFET's with $\mathrm{N}_{2} \mathrm{O}$-based oxides as gate dielectrics has not yet been reported in literature. This work studied the characteristics of off-state $\mathrm{I}_{\mathrm{g}}$ in n-channel MOSFET's with thin $\mathrm{N}_{2} \mathrm{O}$-based gate dielectrics. N-MOSFET's using conventional thermal oxide (OX) and reoxidized $\mathrm{NH}_{3}$-nitrided oxide (RONO) were also investigated for the purpose of comparison.

\section{Experimental}

The n-MOSFET's used in this study were fabricated on p-type (100)-oriented Si wafer (6 8 $\Omega$ $\mathrm{cm})$ using conventional $\mathrm{n}^{+}$polysilicon-gate technology. The channel doping $\left(\sim 2 \cdot 10^{17} \mathrm{~cm}^{-3}\right)$ was controlled by boron implant through a sacrificial oxide which was stripped after the implant, followed by gate dielectrics formation as described in Table 1. All gate oxides were finally annealed in $\mathrm{N}_{2}$ at $950^{\circ} \mathrm{C}$ for $25 \mathrm{~min}$. The final thickness of all gate dielectrics was around $140 \AA$ as measured by $\mathrm{CV}$ technique. No passivation film was used. Since off-state leakage is independent of channel length, devices with larger dimensions $(\mathrm{L} / \mathrm{W}=20 \mu \mathrm{m} / 20 \mu \mathrm{m})$. were adopted in this work to prevent possible punchthrough during measurement and minimize fringe effect. 
Table 1. Preparation sequences of gate oxides employed in this study

\begin{tabular}{cccc}
\hline samples & oxidation & nitridation & reoxidation \\
\hline OX & $\mathrm{O}_{2}, 850^{\circ} \mathrm{C}, 70 \mathrm{~min}$ & $-\cdots---$ & $\cdots--$ \\
RONO & $\mathrm{O}_{2}, 850^{\circ} \mathrm{C}, 60 \mathrm{~min}$ & $\mathrm{NH}_{3}, 950^{\circ} \mathrm{C}, 35 \mathrm{~min}$ & $\mathrm{O}_{2}, 950^{\circ} \mathrm{C}, 30 \mathrm{~min}$ \\
N2ON & $\mathrm{O}_{2}, 850^{\circ} \mathrm{C}, 60 \mathrm{~min}$ & $\mathrm{~N}_{2} \mathrm{O}, 950^{\circ} \mathrm{C}, 10 \mathrm{~min}$ & $\cdots-\cdots$ \\
N2OG & $\mathrm{N}_{2} \mathrm{O}, 950^{\circ} \mathrm{C}, 120 \mathrm{~min}$ & $-\cdots---$ & $-\cdots$ \\
\hline
\end{tabular}

\section{Off-state gate leakage characteristics and discussion}

Fig. 1 shows the gate current $\left(I_{g}\right)$ characteristics of n-MOSFETs with OX, N2ON and RONO, $\mathrm{N} 2 \mathrm{OG}$ gate dielectrics. In the $\mathrm{V}_{\mathrm{d}}$ region $(5 \mathrm{~V} \sim 10 \mathrm{~V})$, where the drain leakage is dominated by B-B tunneling in drain corner, a $V_{d}$-exponentially dependent $I_{g}$ was observed in RONO and N2OG devices, as shown in Fig.1. In contrast, no detectable $I_{g}$ was found in this $V_{d}$ region for $O X$ and N2ON devices. $I_{g}$ only appeared in the high $V_{d}$ region $(>11 \mathrm{~V})$, where avalanche effect occurs in drain junction. F-N tunneling of electrons from $n^{+}$poly-gate cannot account for this low-field $\mathrm{I}_{\mathrm{g}}$, because the slopes of F-N plot for RONO and N2OG devices in low field region, depicted in Fig.2, are much smaller than normal values $(\sim 10 \mathrm{~A} / \mathrm{cm} \bullet \mathrm{V})$, which would yield physically unreasonable low barrier height. While studies performed on MOS capacitors have indicated that the barrier height for e-injection in $\mathrm{N}_{2} \mathrm{O}$-grown oxides is similar to that in pure $\mathrm{SiO}_{2}$ [12]. Mechanism of hot-hole injection from the drain to the gate, proposed in [8], also cannot be responsible for the observed low-field $\mathrm{I}_{\mathrm{g}}$, even if the nitridation-induced barrier height lowering effect is taken into account. We measured the off-state drain and gate leakage current on N2OG device under four different substrate bias. The results are given in Fig. 3. It can be clearly seen that although drain leakage is strongly affected by the avalanche effect in the drain-substrate junction, indicating hole trapping in gate oxide, the corresponding $\mathrm{I}_{\mathrm{g}}$ remains unchanged for all $\mathrm{V}_{\text {sub }}$ bias, suggesting that $I_{g}$ cannot be attributed to hot-hole injection. Similar results were also observed in RONO devices (not shown here). The model of shallow-trap-assisted tunneling of electrons from the gate [14] can readily explain the low-field $I_{g}$ observed in RONO and N2OG devices. This argument is supported below by the channel hot-carrier stress experiments. Presented in Fig. 4 is the measured $\mathrm{I}_{\mathrm{g}}$ after different stress times of channel hot-electron injection. $\mathrm{I}_{\mathrm{g}}$ decreased monotonicly as the $e^{-i n j e c t i o n ~ a n d ~ t r a p p i n g ~ p r o c e e d e d ~ b e c a u s e ~ e l e c t r o n ~ t r a p s ~ a r e ~ f i l l e d ~ b y ~ t h e ~}$ injected electrons. This behaviour is contrary to the hot-hole injection model, since e-trapping should lead to increasing $I_{g}$ due to electric field enhancement in the drain junction. Experiment of hot-hole injection effect on $\mathrm{I}_{\mathrm{g}}$, shown in Fig. 5, further confirms the trap-assisted tunneling mechanism. Off-state $I_{g}$ remains unchanged during the whole hot-hole injection stress since the gate current conduction is not related to the holes but electrons only.

\section{Summary}

Off-state gate current of n-channel MOSFET's with OX, RONO, N2ON, and N2OG oxides as gate dielectrics was investigated in this work. It is revealed that gate current conduction mechanism in low field region is very different for these oxides. Enhanced conductivity is observed in RONO and $\mathrm{N} 2 \mathrm{OG}$ oxides, which is attributed to the trap-assisted tunneling mechanism. Therefore, in view of gate leakage, the method of nitridizing pre-grown thermal oxide is more 
feasible than directly growing oxide in $\mathrm{N}_{2} \mathrm{O}$ ambient, especially in leakage sensitive applications, such as very-low-power battery-based circuits, DRAM cells, etc..

\section{References}

[1] C. Chang and J. Lien, "Cornor-field induced drain leakage in thin oxide MOSFETs," in IEDM Tech. Dig., 1987, pp.714-717.

[2] T. Y. Chan, J. Chen, P. K. Ko, and C. Hu, "The impact of gate-induced drain leakage current on MOSFET scaling," in IEDM Tech. Dig., 1987, pp.718-721.

[3] C. Chang, S. Haddad, B. Swaminathan, and J. Lien, "Drain-avalanche and hole-trapping induced gate leakage in thin-oxide MOS devices," IEEE Electron Device Lett., vol.9, no.11, pp.588-590, 1988.

[4] G. Samachisa et al., "A 128K flash EEPROM using double-polysilicon technology," IEEE J. Solid-State Circuits, vol. SC-22, no.5, p.676, 1987.

[5] H. Kume et al., "A flash-erase EEPROM cell with an asymmetric source and drain structure," in IEDM Tech. Dig., 1987, pp.560-563.

[6] G. Verma and N. Mielke, "Reliability performance of ETOX based flash memories," in 26th Proc. IEEE Reliability Phys. Symp., Apr. 1988, p.158.

[7] J. Chen, T. Y. Chan, P. K. Ko, and C. Hu, "Gate current in off-state MOSFET," IEEE Electron Device Lett., vol.10, no.5, pp.203-205, 1989.

[8] A. T. Wu, S. H. Lee, V. Murali, and M. Garner, "Off-state gate current in n-channel MOSFET's with nitrided oxide gate dielectrics," IEEE Electron Device Lett., vol.11, no.11, pp.499-501, 1990.

[9] A. Uchiyama, H. Fukuda, T. Hayashi, T. Iwabuchi, and S. Ohno, "High-performance dual-gate sub-halfmicron CMOSFETs with 6-nm-thick nitrided $\mathrm{SiO}_{2}$ films in an $\mathrm{N}_{2} \mathrm{O}$ ambient," in IEDM Tech. Dig., 1990, pp.425-428.

[10] H. Hwang, W. Ting, D-L. Kwong and J. Lee, "Electrical and reliability characteristics of ultrathin oxynitride gate dielectric prepared by rapid thermal processing in $\mathrm{N}_{2} \mathrm{O}$," in IEDM Tech. Dig., 1990, pp.421-424.

[11] Z. H. Liu, H. J. Wann, P. K. Ko, C. Hu, and Y. C. Cheng, "Effects of $\mathrm{N}_{2} \mathrm{O}$ anneal and reoxidation on thermal oxide characteristics," IEEE Electron Device Lett., vol.13, pp.402-405, 1992.

[12] A. B. Josh1, G. Yoon, J. Kim, G. Q. Lo, and D-L. Kwong, "High-Field Breakdown in Thin Oxides Grown in $\mathrm{N}_{2} \mathrm{O}$ Ambient," IEEE Trans. Electron Devices, vol.40, no.8, pp.1437-1444, 1993.

[13] A. Ditali, V. Mathews, and P. Fazan, "Hot-carrier-induced degradation of gate dielectrics grown in nitrous oxide under accelerated aging," IEEE Electron Device Lett., vol.13, no.10, pp.538-540, 1992.

[14] H. Wong and Y. C. Cheng, "Electronic conduction mechanisms in thin oxynitride films," J. Appl. Phys. vol.70(2), p.1078, 1991. 


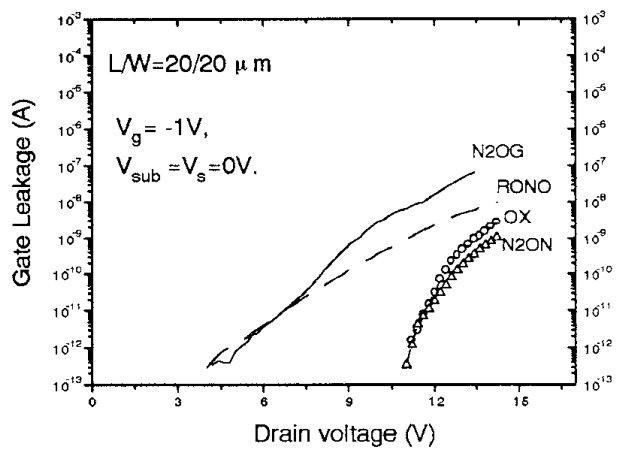

Fig. 1. Gate leakage current for N2OG (full line), RONO (dashed line), OX (circles), and N2ON (up triangles) devices.

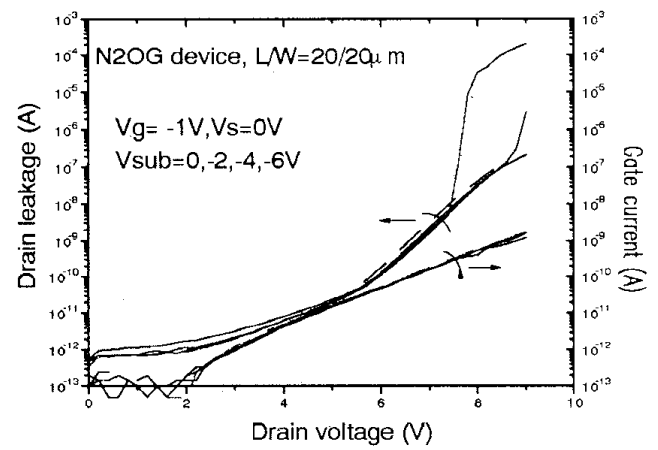

Fig. 3. Drain and gate leakage current at $V_{\text {sub }}=0,-2,-4,-6 \mathrm{~V}$ (from right to left).

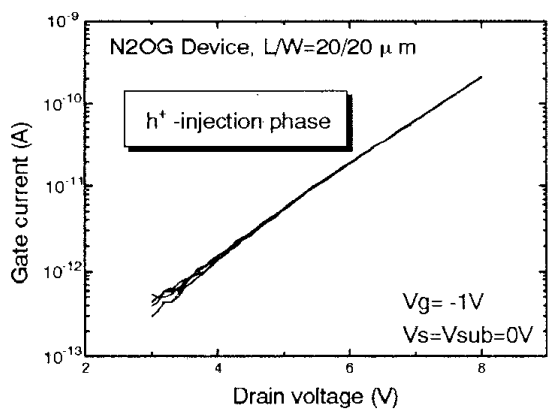

Fig. 5. Off-state gate current measured at stress time $=0,50,400,2200$, and 4000 s. Hot-hole stress condition: $\mathrm{V}_{\mathrm{g}}=0.7 \mathrm{~V}, \mathrm{~V}_{\mathrm{d}}=7 \mathrm{~V}, \mathrm{~V}_{\mathrm{s}}=\mathrm{V}_{\mathrm{sub}}=0 \mathrm{~V}$.

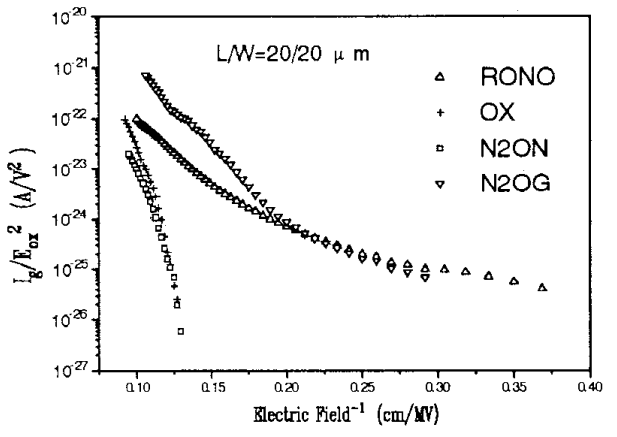

Fig. 2. F-N plot for gate current of the n-MOSFETs with OX, RONO, N2ON and N2OG gate dielectrics.

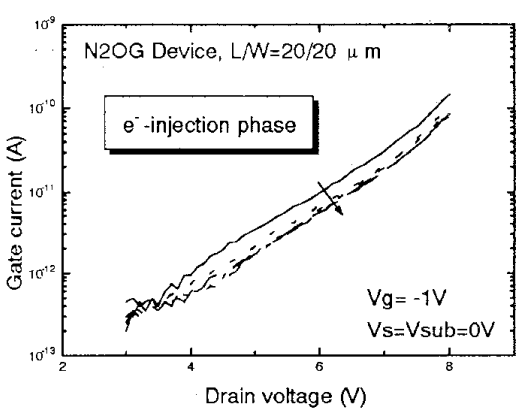

Fig. 4. Off-state gate current measured at stress time $=0,50,400,2200$, and $4000 \mathrm{~s}$ (in the arrow direction). Hot-electron stress condition: $\mathrm{V}_{\mathrm{g}}=7.5 \mathrm{~V}$, $\mathrm{V}_{\mathrm{d}}=7 \mathrm{~V}, \mathrm{~V}_{\mathrm{s}}=\mathrm{V}_{\text {sub }}=0 \mathrm{~V}$. 